• 研究报告・

\title{
滇杨种群遗传多样性与遗传结构
}

\author{
张亚红 ${ }^{1}$ 贾会霞 王志涁 $^{2}$ 孙 佩 ${ }^{1}$ 曹德美 ${ }^{1}$ 胡建军 $1^{*}$ \\ 1 (林木遗传育种国家重点实验室, 国家林业和草原局林木培育重点实验室, 中国林业科学研究院林业研究所, 北京 100091) \\ 2 (张家口市金沙滩林场, 河北怀安 076150)
}

摘要: 滇杨(Populus yunnanensis)是我国西南地区的特有树种, 具有速生、易无性繁殖、适应性强等优良特性，是 典型的南方型杨属树种。研究滇杨遗传多样性及种群结构对其种质资源的收集、保存和利用具有重要的意义。本 研究从我国滇杨主要分布区云南和四川共采集了6个种群, 包括云南的昭通(ZT)、会泽 (HZ)、訔月 (SM)、洱原 $(\mathrm{EY})$ 、 拉市海(LS)以及四川的美姑(MG), 共64个个体, 利用34对SSR分子标记和3对cpDNA叶绿体标记开展遗传多样性 与遗传结构研究。SSR引物共检测到 154 个等位基因, 平均等位基因数为 4.529 , 观测杂合度 $(\mathrm{Ho})$ 与期望杂合度 $(\mathrm{He})$ 分别为 0.552 和 0.472 , 遗传分化系数 $(F s t)$ 平均值为 0.238 , 多态性信息含量指数 $(P I C)$ 平均值为 0.421 , 基因流 $(N m)$ 为 0.806 。滇杨的遗传结构分析(DAPC)与遗传距离的主坐标分析(PCoA)、UPGMA聚类分析均将6个种群划分为 3 个亚 类: 第I亚类包括昭通种群、会泽种群和嵩明种群的 4 个个体, 第II亚类包括嵩明种群的 6 个个体以及洱源种群和拉 市海种群, 第III亚类为美姑种群; 嵩明种群包含第I和第II两个亚类的混合遗传成分。3个cpDNA联合序列中共检测 到 35 个变异位点, 分为 13 个单倍型, 其中单倍型H5在种群中分布最为广泛, 其余的单倍型均为种群特有的单倍 型。分子方差分析(AMOVA)表明种群内的遗传变异大于种群间变异。研究表明滇杨不同种群的遗传分化具有地 域性, 可选择就地保护; 昭通种群遗传多样性最高, 且包含7种叶绿体单倍型, 单倍型类型最多, 应优先保护。

关键词：滇杨；遗传多样性；遗传结构；分子标记; SSR; cpDNA

\section{Genetic diversity and population structure of Populus yunnanensis}

Yahong Zhang ${ }^{1}$, Huixia Jia ${ }^{1}$, Zhibin Wang ${ }^{2}$, Pei Sun ${ }^{1}$, Demei Cao ${ }^{1}$, Jianjun $\mathrm{Hu}^{1 *}$

1 State Key Laboratory of Tree Genetics and Breeding, Key Laboratory of Tree Breeding and Cultivation of State Forestry and Grassland Administration, Research Institute of Forestry, Chinese Academy of Forestry, Beijing 100091 2 Zhangjiakou Jinshatan Forest Farm, Huaian, Hebei 076150

\begin{abstract}
Populus yunnanensis is an endemic tree species to Southwestern China. It is a typical southern Populus species that is fast-growing species with easy to clone propagules and is highly adaptable. It is important to research the genetic diversity and population structure of $P$. yunnanensis for the collection, preservation and utilization of the germplasm resources. In this study, 64 individuals were collected from six populations, spaning the main distribution areas of P. yunnanensis, including Zhaotong (ZT), Huize (HZ), Songming (SM), Eryuan (EY), Lashihai (LS) and Sichuan Meigu (MG). A total of 34 pairs of SSR primers and three pairs of cpDNA primers were used to determine out the genetic diversity and genetic structure. A total of 154 alleles were detected by SSR primers in $P$. yunnanensis. The average number of alleles was 4.529 . The observed heterozygosity $(\mathrm{Ho})$ and expected heterozygosity $(\mathrm{He})$ were 0.552 and 0.472 , respectively. And the average genetic differentiation coefficient (Fst) was 0.238 . The average polymorphism information content $(\mathrm{PIC})$ was 0.421 and the gene flow $(\mathrm{Nm})$ was 0.806 . The results of the DAPC, PCoA and UPGMA analyses showed that the six populations can be divided into three sub-categories: Group I included ZT, HZ and four individuals of SM. Group II included EY, LS and the six remaining individuals of SM; and group III included MG; SM population include mixed genetic components from I and II. A total of 35 variable sites were detected in the three cpDNA combinations, forming 13 haplotypes. Among them, haplotype H5 was the most widely distributed in the population, while the remaining ones were of private haplotypes. Analysis of molecular variance (AMOVA) showed that genetic variation within the population was greater than between populations. The study clarifies that $P$. yunnanensis has geographical distribution characteristics and is suited to in situ conservation. As ZT population has the highest genetic diversity and contains seven chloroplast haplotypes, it should be given protection priority.
\end{abstract}

收稿日期: 2019-01-21; 接受日期: 2019-04-18

基金项目: 中央级公益性科研院所基本科研业务费专项资金(CAFYBB2017ZY008)

* 通讯作者 Author for correspondence. E-mail: hujj@caf.ac.cn 
Key words: Populus yunnanensis; genetic diversity; genetic structure; molecular marker; SSR; cpDNA

遗传多样性是物种生存适应的基础, 遗传多样 性水平的高低反映了物种在自然环境中适应性的 强弱, 因此, 对物种遗传多样性的研究可对物种现 有的生存方式及状态进行有效的评估(尚占环和姚 爱兴, 2002)。物种遗传多样性的降低意味着其遗传 变异水平的降低和适应性的减弱, 这将会威胁到物 种的长期生存(Wang et al, 2011)。在木本植物中, 大 多数物种由于分布广泛、异交繁殖, 会表现出种群 内遗传变异高于种群间遗传变异的现象(Roy et al, 2004; DiFazio et al, 2011), 而少数树种则会由于树 种的分布范围比较分散, 呈现出种内遗传变异水平 低于种间变异的现象(Wang et al, 2014)。

滇杨(Populus yunnanensis)作为我国西南地区 的特有杨属树种, 分布区主要集中在云南、四川等 地。云南、四川地区地理环境和气候类型复杂多样, 孕育了丰富的生物资源。该地区杨树资源丰富、种 类繁多、分布广泛、变异丰富, 拥有较多变种和天 然杂种, 是我国杨树的自然分布和变异中心之一 (赵能和刘军, 1994; 余树全等, 2003; 龚固堂, 2004)。滇杨喜温凉、湿润气候, 多生长于 1,300-3,200 m的高海拔范围内, 部分可达3,700 m, 在速生、无性繁殖、抗病等方面表现良好, 在水土 保持和生物多样性的维持中也具有重要的作用, 因 此在南方树种中占有特殊的位置(万雪琴等, 2009; 何承忠等, 2010)。滇杨树形通直, 出材率短期可达 较高水平, 木质部纤维较长且柔韧性好, 是造纸、 建筑、胶合板以及家具等的优良用材。滇杨嫩芽分 泌强粘性的脂类物质, 也被用于黄褐色染料的加工 利用(颜路茜等, 2016)。近十几年来, 由于乡村城镇 化、道路、水库等基本建设发展, 使得滇杨天然资 源越来越少(何承忠等, 2010), 所以, 研究滇杨遗传 多样性和遗传结构对滇杨资源的合理保护与遗传 改良具有重要意义。

随着分子生物学技术的快速发展和不断完善, 分子标记已被普遍应用于种群遗传多样性和遗传 结构等研究中(陈新民等, 2003; 何承忠等, 2010)。 分子标记种类多样, 其中, 微卫星序列 (simple sequence repeats, SSR)在物种中为双亲遗传, 具有
操作简单、多态性高、覆盖面广、共显性、重复性 高等优点(Du et al, 2012); cpDNA (chloroplast DNA) 基于叶绿体基因组开发, 系母系遗传, 非编码区序 列和编码区序列进化速率不同, 能很好地表现种间 和种内的变异(Semerikova \& Semerikov, 2014); 结 合核基因与叶绿体基因两个方面可以对物种遗传 多样性的研究提供更全面的参考。目前, 利用SSR 和cpDNA这两种分子标记对遗传多样性进行研究 已经在胡杨(P. euphratica) (Zeng et al, 2018)、山杨( $P$. davidiana) (Zheng et al, 2017)等多个杨属树种中应 用, 相比之下, 滇杨的研究仍以AFLP (amplified fragment length polymorphism)、SRAP (sequence related amplified polymorphism)等单一分子标记为 主(何承忠等, 2009; 纵丹等, 2014; 颜璐茜等, 2016), 利用多种分子标记进行的研究尚未见报道。

本研究从我国滇杨集中分布区采集样本, 采用 SSR和cpDNA两种分子标记相结合的方法，从核基 因水平与叶绿体基因水平检测滇杨的遗传资源现 状和种群间与种群内的变异情况, 阐明滇杨的遗传 多样性和地理分布特点, 为滇杨的进一步研究和保 护以及遗传改良提供理论基础。

\section{材料与方法}

\section{1 材料准备}

滇杨的主要分布区集中于我国的西南地区, 本 研究从云南昭通 $(\mathrm{ZT})$ 、会泽 $(\mathrm{HZ})$ 、嵩明 $(\mathrm{SM})$ 、洱源 (EY)、拉市海(LS)和四川美姑(MG)采集了6个种群, 共64个个体(表1); 在2016年12月至2017年1月期间 采集枝条, 每个采样地采集6-12个个体, 每个个体 间距在 $100 \mathrm{~m}$ 以上, 最大限度避免采集无性繁殖植 株。对所采集的个体利用GPS定位并标记记录。将 采集到的枝条在中国林业科学研究院温室进行扞 插繁殖, 从扞插苗上采集嫩叶, 迅速用液氮处理后 放置于 $-80^{\circ} \mathrm{C}$ 超低温冰箱保存。

\subsection{DNA提取}

采用改良后的CTAB提取法(Schuelke, 2000; Allen et al, 2006)提取总DNA, 使用紫外分光光度计 检测样品的DNA浓度和纯度, 并将浓度稀释到 
表1 滇杨各种群采样地地理信息及采样数

Table 1 Geographic information and sample size of Populus yunnanensis

\begin{tabular}{llllll}
\hline 种群 Population & 代号 Code & 样本量 Sample size & 纬度 Latitude & 经度 Longitude & 海拔 Altitude (m) \\
\hline 昭通 Zhaotong & ZT & 12 & $27^{\circ} 33^{\prime} 52^{\prime \prime}-27^{\circ} 38^{\prime} 29^{\prime \prime}$ N & $103^{\circ} 45^{\prime} 05^{\prime \prime}-103^{\circ} 46^{\prime} 43^{\prime \prime}$ E & $1,802-1,914$ \\
会泽 Huize & HZ & 12 & $26^{\circ} 12^{\prime} 07^{\prime \prime}-26^{\circ} 23^{\prime} 42^{\prime \prime}$ N & $103^{\circ} 15^{\prime} 19^{\prime \prime}-103^{\circ} 24^{\prime} 09^{\prime \prime}$ E & $2,118-2,303$ \\
嵩明 Songming & SM & 10 & $25^{\circ} 12^{\prime} 07^{\prime \prime}-25^{\circ} 17^{\prime} 42^{\prime \prime}$ N & $103^{\circ} 02^{\prime} 42^{\prime \prime}-103^{\circ} 03^{\prime} 43^{\prime \prime}$ E & $1,900-1,930$ \\
洱源 Eryuan & EY & 12 & $26^{\circ} 05^{\prime} 56^{\prime \prime}-26^{\circ} 08^{\prime} 17^{\prime \prime}$ N & $99^{\circ} 58^{\prime} 13^{\prime \prime}-100^{\circ} 00^{\prime} 08^{\prime \prime}$ E & $2,056-2,060$ \\
拉市海 Lashihai & LS & 12 & $26^{\circ} 51^{\prime} 03^{\prime \prime}-27^{\circ} 00^{\prime} 28^{\prime \prime} \mathrm{N}$ & $100^{\circ} 08^{\prime} 58^{\prime \prime}-100^{\circ} 15^{\prime} 24^{\prime \prime}$ E & $2,418-2,657$ \\
美姑 Meigu & MG & 6 & $28^{\circ} 19^{\prime} 40^{\prime \prime}-28^{\circ} 20^{\prime} 09^{\prime \prime} \mathrm{N}$ & $103^{\circ} 08^{\prime} 22^{\prime \prime}-103^{\circ} 08^{\prime} 44^{\prime \prime}$ E & $1,944-2,027$ \\
\hline
\end{tabular}

$50 \mathrm{ng} / \mathrm{uL}$ ，置于 $-20^{\circ} \mathrm{C}$ 冰箱中备用。

\subsection{SSR标记程序}

从杨树SSR数据库中选取 300 对SSR引物, 随机 选取8个样本进行初步篮选, 挑选出多态性高、扩增 稳定、在杨树19条染色体上均匀分布的34对引物(表 2), 使用 TP-M13-SSR 毛细管电泳苂光检测 法 (Schuelke, 2000)对所有个体进行PCR扩增和产物测 定，利用3条引物(反向接有苂光标签的M13引物, 正向接有M13序列的SSR正向引物和SSR反向引物) 进行 PCR扩增, 反应体系和程序按照贾会霞等 (2015)进行。SSR基因型在ABI 3130XL自动测序仪 (Life Technologies, Foster City, CA, USA)上解析, 使 用Gene-Marker 1.65进行等位基因测定, 选取GS500 作为内标。

\section{4 叶绿体序列程序}

使用叶绿体trnK、rpoC1、atpF区域引物CO2、 CO5、CO9 (表3)进行PCR反应扩增, 反应体系和 程序按照陈珂(2007)进行, 所用试剂均为 TaKaRa 公司提供, 在ABI 3130xl自动测序仪上分析反应混 合物。

\subsection{SSR数据分析}

采用GENALEX 6.503软件包(Peakall \& Smouse, 2006)计算等位基因数 $(\mathrm{Na})$ 、有效等位基因数 $(\mathrm{Ne})$ 、观测杂合度 $(\mathrm{Ho})$ 、期望杂合度 $(\mathrm{He}) 、$ Shannon’s 信息指数 $(I)$ 、种群内部近交系数 $(F)$ 、Nei's遗传距离 和基因流 $(\mathrm{Nm})$ 。为了衡量群体遗传分化程度, 利用 GenALEx 6.503统计各位点的近交系数(Fis)和遗传 分化系数(Fst)等F统计量。

使用Cervus 3.0.7计算SSR引物的多态性信息含 量(PIC), 评价所用34对引物在滇杨遗传多样性分 析中的多态性信息含量指数, 其值越大, 表明多态 性越高, 越适合遗传多样性研究。

使用R X64 3.4.3中2.1.1版本的adegenet软件包
的DAPC算法(Jombart et al, 2010)进行遗传结构分 析。这种算法不需要考虑Hardy-Weinberg平衡和连 锁不平衡检测。DAPC算法并不是基于原始数据进 行的计算, 而是通过对数据进行主成分特征值 (Principal Component, PC)转换后再进行计算, 整个 过程可以保留所有的PC, 以确保算法的准确性。使 用optim. a. score函数选择最佳PC数量, 在保证算法 准确性的同时减少计算时间。使用clusters函数来确 定最佳的 $\mathrm{K}$ 值, 即群体遗传结构的最佳群体数, 绘 制种群遗传结构分布图。

为了估计种群间及种群内的遗传变异, 使用 GenALEx 6.503软件包对物种水平进行分子方差分 析(AMOVA)。采用PHYLIP 3.6软件包(Retief, 1999) 以Nei's所得遗传距离作为进一步分析的参数, 完成 非加权成组配对算术平均法(UPGMA)的树状聚类 分析, bootstrap设置为 1,000 次。主坐标分析(PCoA) 以Nei's遗传距离为参数, 用GenALEx 6.503软件 完成。

\section{6 cpDNA序列分析}

为分析滇杨单倍型种类, 利用 DNASTAR Lasergene 7.1软件(Burland, 2000)中的seqman程序 对cpDNA序列进行核对以及正反向序列拼接，并将 3条片段合并成1条序列, 使用BioEdit 7.05 (Tippmann, 2004)对序列进行对齐并进行剪切编辑。用 DnaSP 5.1软件(Rozas et al, 2003)进行单倍型分类, 并统计多态位点数, 计算单倍型多态性 $(h)$ 和核苷酸 多态性 $(\pi)$ 。

分析各单倍型之间的关系，用软件MEGA 6.0 分析核苷酸组成(Kumar et al, 2016), 以Nei’s遗传距 离作为参数, 以胡杨的DNA序列作为外类群, 完成 最大简约法(maximum parsimony, MP)的树状聚类 分析, bootstrap 设置为 1,000 次。使用NETWORK 4.6.1.3构建单倍型之间的中央链接网络图(Bandelt 


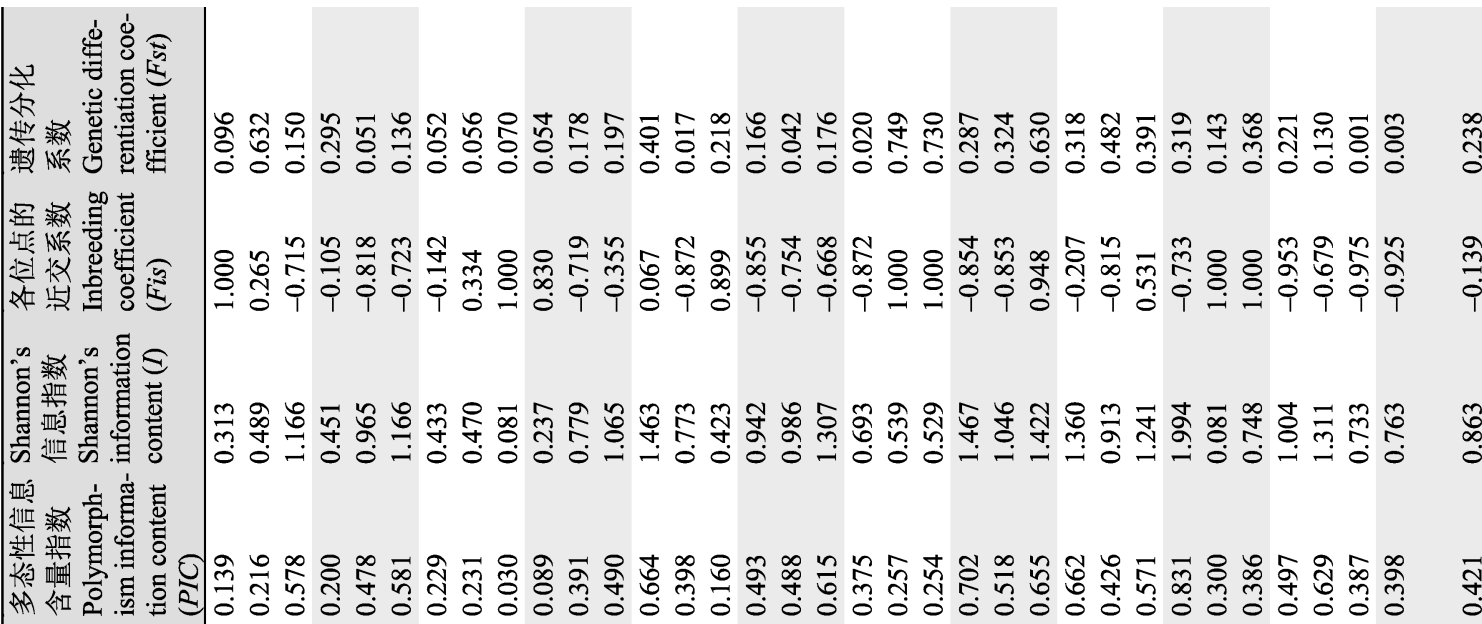

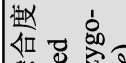

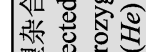

䊉

坃

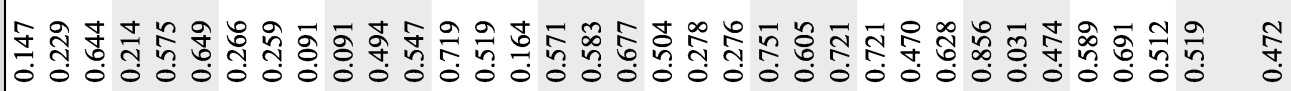
低方总 窝品

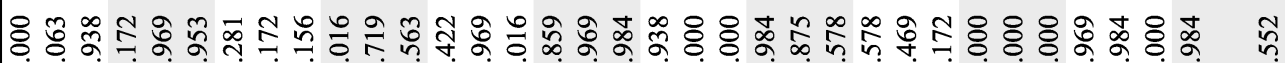
흘 क्र

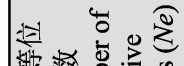

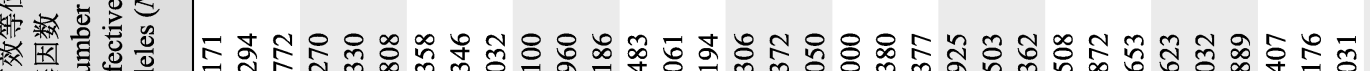
巡形会察 函苍皆 건 은 
et al, 1999; Polzin \& Daneshmand, 2003)。构建网络 图时包含了所有信息位点, 各个位点设置相同的权 重。在单倍型中央链接(Median Joining, M-J)网络图 中, 越处于边缘位置的单倍型被认为是越年轻的单 倍型, 越原始的单倍型则处于更为中间的位置 (Golding, 1987; Crandall \& Templeton, 1993)。

\section{结果}

\subsection{SSR位点的多样性}

34对 SSR 引物在滇杨样品中共检测到154个等 位基因, 每个位点扩增条带数在2-10之间, 平均每 个位点等位基因数 $(\mathrm{Na})$ 为 4.529 , 有效等位基因数 $(\mathrm{Ne}$ )为2.262 (表2), 扩增片段大小在130-250 bp之 间。Shannon's信息指数(I)的变异范围为0.081-1.994, 平均为 0.863 。物种水平上观测杂合度 $(H o)$ 和期望杂 合度 $(H e)$ 分别为 0.552 和 0.472 。34 个SSR位点的 $F$ 统 计量检测显示, 滇杨的遗传分化系数 (Fst) 为 0.238 , 近交系数(Fis)为 -0.139 , 说明滇杨的遗传分化水平 适中。各位点的多态性信息含量指数 $(P I C)$ 在 0.030 0.831 之间, 平均为 0.421 , 表明所选SSR引物均能有 效地揭示滇杨遗传多样性。

\section{2 滇杨种群遗传多样性}

6 个滇杨种群遗传多样性分析结果(表4)显示,
各种群遗传多样性水平存在差异, 不同分子标记所 得遗传多样性大小也有差异。在SSR标记中, 6 个种 群的Shannon's信息指数 $(I)$ 在 $0.473-0.639$ 之间, 平均 为 0.561 。其中, 美姑种群呈现出了较低的遗传多样 性, Shannon's信息指数 $(I)$ 为 0.473 , 观测杂合度 $(H o)$ 和期望杂合度 $(\mathrm{He})$ 分别为 0.495 和 0.324 , 其余种群 的遗传多样性差异不明显。基于叶绿体数据分析可 知, 昭通种群的遗传多样性最高, 所包含的单倍型 也最多，包含了7种单倍型，其中特有单倍型6种， 单倍型多态性 $(h)$ 为 0.864 , 核苷酸多样性 $(\pi)$ 为 0.00055。洱源种群、拉市海种群和美姑种群分别包 含单倍型 4 种、 3 种和 2 种，遗传多样性处于中等水 平。会泽种群和嵩明种群由于只包含1种单倍型, 从 cpDNA标记上不能显示出其种群遗传多样性水平 高低。

\section{3 滇杨种群遗传结构}

利用R语言DAPC软件包分析滇杨种群遗传结 构, 结果显示(图1), 当 $\mathrm{K}=3$ 时, 美姑种群个体与其 他种群分离，此时，64份滇杨样品划分为3个不同的 亚类。嵩明地区为I和II两亚类的过渡区域, 包含I和 II两个亚类的混合遗传成分，即第I亚类包括昭通种 群、会泽种群和嵩明种群的 4 个个体; 第II亚类包括 嵩明种群的剩余6个个体、洱源种群和拉市海种群;

表3 用于滇杨PCR扩增的3个cpDNA引物序列信息

Table 3 Three chloroplast DNA primers sequence information of Populus yunnanensis

\begin{tabular}{llll}
\hline 名称 Name & 区域 Primer area & 正向序列 Forward primer sequence (5'-3') & 反向序列 Reverse primer sequence (5'-3’) \\
\hline CO2 & trnK & AGATGGAAAAAAGAGAGGATAGAGG & CAAATAATATCCAAATACCAAACCC \\
CO5 & rpoC1 & CGAATGGAAGACATAGACAAGT & AAGTGACCTTCGGGAGCTTCTC \\
CO9 & $a t p F$ & TTGAAGTCCAGACAGAGCAGGTTAC & GGTCAAACAACTATTCAAAGTCCCT \\
\hline
\end{tabular}

表4 基于SSR和cpDNA所得的滇杨遗传多样性信息表。种群代号同表 1 。

Table 4 Genetic diversity of Populus yunnanensis based on SSR and cpDNA. Population codes see Table 1.

\begin{tabular}{|c|c|c|c|c|c|c|c|c|c|}
\hline $\begin{array}{l}\text { 种群 } \\
\text { Popula- } \\
\text { tion }\end{array}$ & $\begin{array}{l}\text { 等位基因 } \\
\text { - Number of } \\
\text { alleles }(\mathrm{Na})\end{array}$ & $\begin{array}{l}\text { 有效等位 } \\
\text { 基因 } \\
\text { Number of } \\
\text { effective } \\
\text { alleles }(\mathrm{Ne})\end{array}$ & $\begin{array}{l}\text { 观测杂合度 } \\
\text { Observed } \\
\text { heterozygo- } \\
\text { sity }(\mathrm{Ho})\end{array}$ & $\begin{array}{l}\text { 期望杂合度 } \\
\text { Expected } \\
\text { heterozygo- } \\
\text { sity }(H e)\end{array}$ & $\begin{array}{l}\text { Shannon's } \\
\text { 信息指数 } \\
\text { Shannon's } \\
\text { information } \\
\text { content (I) }\end{array}$ & $\begin{array}{l}\text { 近交系数 } \\
\text { Inbreeding } \\
\text { coefficient } \\
(F)\end{array}$ & $\begin{array}{l}\text { 单倍型多态性 } \\
\text { Haplotype } \\
\text { diversity }(h)\end{array}$ & $\begin{array}{l}\text { 核苷酸 } \\
\text { 多样性 } \\
\text { Nucleotide } \\
\text { diversity }(\pi)\end{array}$ & $\begin{array}{l}\text { 单倍型组成(个体数) } \\
\text { Haplotype composition } \\
\text { (No. of individuals) }\end{array}$ \\
\hline $\mathrm{ZT}$ & 2.000 & 1.695 & 0.537 & 0.345 & 0.514 & -0.439 & 0.864 & 0.00055 & $\begin{array}{l}\text { H1(3); H2(1); H3(1); H4(1); } \\
\text { H5(4); H6(1); H7(1) }\end{array}$ \\
\hline $\mathrm{HZ}$ & 2.000 & 1.759 & 0.522 & 0.345 & 0.528 & -0.432 & - & - & H5(12) \\
\hline SM & 2.265 & 1.806 & 0.532 & 0.368 & 0.585 & -0.313 & - & - & H5(10) \\
\hline EY & 2.559 & 1.904 & 0.520 & 0.385 & 0.639 & -0.190 & 0.455 & 0.00013 & $\begin{array}{l}\text { H5(9); H10(1); H11(1); } \\
\text { H12(1) }\end{array}$ \\
\hline LS & 2.441 & 1.862 & 0.559 & 0.390 & 0.627 & -0.260 & 0.378 & 0.00025 & H5(10); H8(1); H9(1) \\
\hline MG & 1.794 & 1.623 & 0.495 & 0.324 & 0.473 & -0.454 & 0.333 & 0.00017 & H5(5); H13(1) \\
\hline $\begin{array}{l}\text { 平均 } \\
\text { Mean }\end{array}$ & 2.177 & 1.775 & 0.528 & 0.360 & 0.561 & -0.341 & 0.402 & 0.00020 & \\
\hline
\end{tabular}



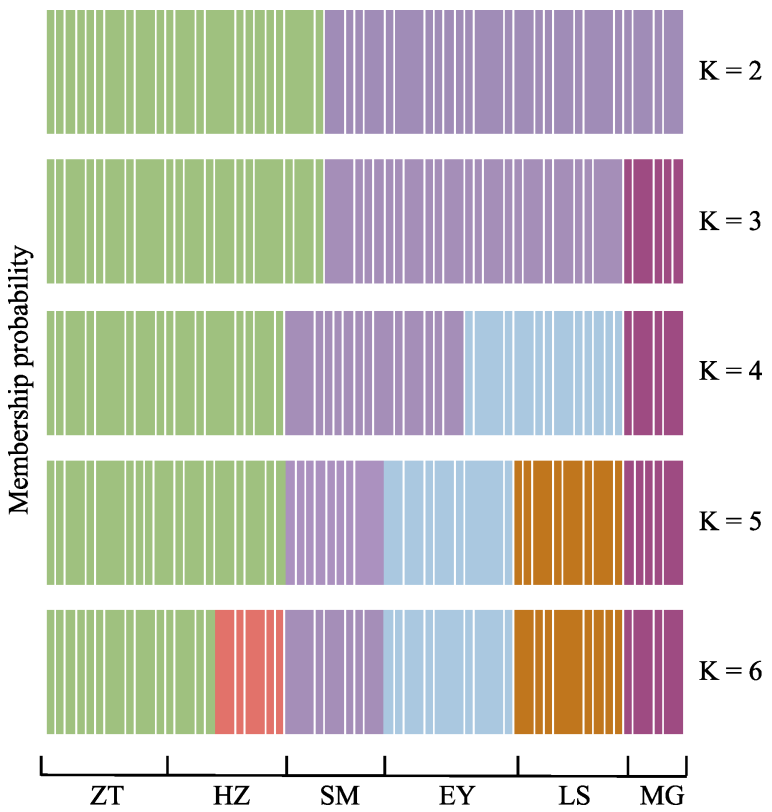

图1 基于DAPC的滇杨个体分布图 $(K=2,3,4,5,6)$ 。种群 代号同表1。

Fig. 1 Cluster membership probabilities of each genet based on the discriminant functions of DAPC $(\mathrm{K}=2,3,4,5,6)$. Population codes see Table 1.

第III亚类包含1个种群(美姑)。随着划分类群的增多， 滇杨种群在遗传结构的分布上也有了更加细致的 划分, 当 $\mathrm{K}=6$ 时, 即划分类群与种群数相同, 只有 昭通种群和会泽种群在遗传结构的划分上产生了 少量的混杂。

为了进一步探讨滇杨种群间的遗传关系, 对所 有滇杨个体进行主坐标分析(PCoA)(图2A)并基于 UPGMA进行聚类(图2B), 结果与DAPC分析的基本

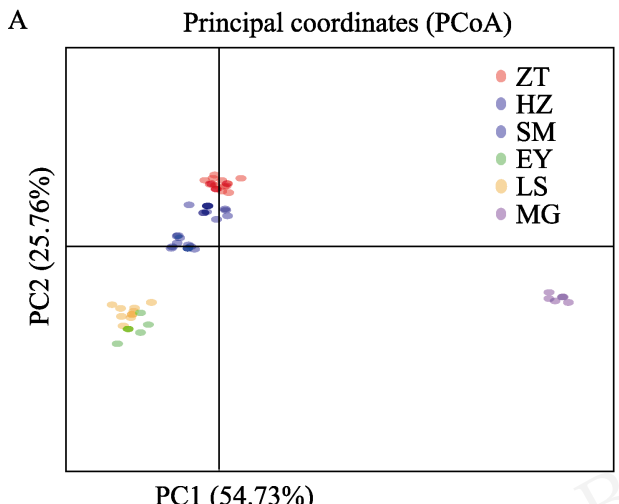

一致，将滇杨遗传结构划分为3个亚类，地理位置 相近的种群依次划分至同一亚类群中，表明滇杨 种群间具有明显的地理区域特性。通过AMOVA分 析(表5)可知, 滇杨遗传变异的主要来源是种群内 个体间的变异(82\%), 种群间的遗传变异占比较小 (18\%)。检测各种群间的遗传分化系数(Fst)和基因 流大小 $(\mathrm{Nm})$ (表6)可知, 6 个滇杨种群间的遗传分化 系数分布范围为 0.081-0.434，基因流水平为 0.327-2.837。其中，相同遗传亚类中种群间遗传分 化较小, 基因流大, 如昭通种群和会泽种群的遗传 分化系数和基因流分别为 0.081 和 2.837 ，拉市海种 群和洱源种群遗传分化系数和基因流分别为 0.101 和2.216; 而来自不同遗传亚类的种群间遗传分化大, 基因流小，如昭通种群和拉市海种群的遗传分化系 数和基因流分别为 0.266 和 0.689 , 昭通种群和美姑 种群的遗传分化系数和基因流分别为 0.434 和 0.327 。

\section{4 系统发育和单倍型分布}

对滇杨64个个体的3个cpDNA片段(CO2、CO5、 CO9)进行串联合并、对齐排列后序列总长度为 4,016 bp, 共发现35个变异位点(表7), 可划分为 13 个单倍型 $(\mathrm{H} 1-\mathrm{H} 13)$ (表4)。以胡杨的DNA序列作为 外类群，对 13 个单倍型基于最大简约法进行聚类 (图3C), 并进行中央链接网络图分析(图3A，B), 结 果发现单倍型 $\mathrm{H} 5$ 频率最高, 为所有种群共享, 且最 先被划分出来，处于中央网络图的中间位置，为祖 先单倍型，其余单倍型均为种群内特有单倍型，昭

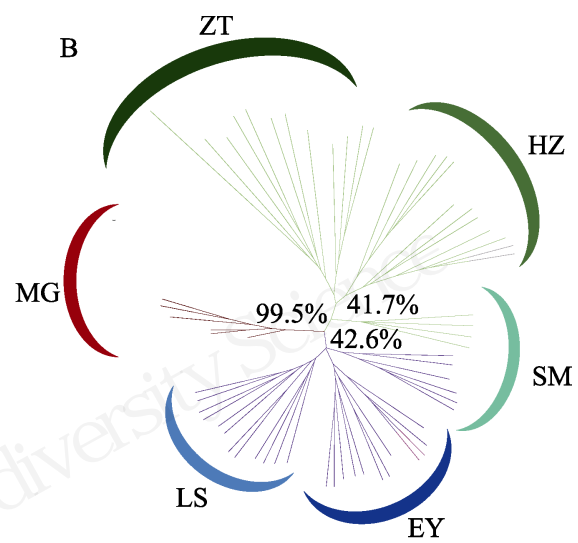

图2 滇杨主坐标分析图及聚类图。(A)个体主坐标分析(PCoA); (B)依据SSR标记基于遗传距离的UPGMA聚类分析，百分比 表示 1,000 次bootstrap值的比例。种群代号同表 1 。

Fig. 2 Principal coordinates analysis and clustering dendrogram of Populus yunnanensis. (A) Principal coordinates analysis; (B) UPGMA dendrogram based on genetic distance with SSR data. The percentage of replicate trees in which the associated taxa clustered together in the bootstrap test (1,000 replicates) are shown next to the branches. Population codes see Table 1. 
表5 基于SSR和cpDNA对种群内和种群间分子变异的方差分析

Table 5 Analysis of molecular variation (AMOVA) within and among populations based on the SSR and cpDNA

\begin{tabular}{|c|c|c|c|c|c|c|c|c|}
\hline \multirow[t]{2}{*}{$\begin{array}{l}\text { 变异来源 } \\
\text { Source of } \\
\text { variation }\end{array}$} & \multirow[t]{2}{*}{$\begin{array}{l}\text { 自由度 } \\
\mathrm{df}\end{array}$} & \multicolumn{2}{|c|}{$\begin{array}{l}\text { 变异值 } \\
\text { Estimated variance of components }\end{array}$} & \multicolumn{2}{|c|}{$\begin{array}{l}\text { 变异来源占比 } \\
\text { Percentage of variation (\%) }\end{array}$} & \multicolumn{2}{|c|}{$\begin{array}{l}\text { 遗传分化系数 } \\
\text { Genetic differentiation } \\
\text { coefficient }(F s t)\end{array}$} & \multirow[t]{2}{*}{$\begin{array}{l}\text { 基因流 } \\
\text { Gene flow }(\mathrm{Nm})\end{array}$} \\
\hline & & SSR & cpDNA & SSR & cpDNA & SSR & cpDNA & \\
\hline $\begin{array}{l}\text { 种群间 } \\
\text { Among population }\end{array}$ & 5 & 1.966 & 9.663 & 18 & 15 & & & \\
\hline $\begin{array}{l}\text { 种群内 } \\
\text { Within populations }\end{array}$ & 59 & 9.016 & 39.047 & 82 & 85 & & & \\
\hline 总计 Total & 64 & 10.982 & 48.710 & 100 & 100 & 0.237 & 0.148 & 0.806 \\
\hline
\end{tabular}

表6 种群间遗传分化系数(Fst，对角线上方)和基因流( Nm, 对角线下方)。种群代号同表1。

Table 6 Genetic differention (Fst, above diagonal) and gene flow (Nm, below diagonal) among populations. Population codes see Table 1.

\begin{tabular}{lllllll}
\hline & ZT & HZ & SM & EY & LS & MG \\
\hline ZT & - & 0.081 & 0.182 & 0.227 & 0.266 & 0.434 \\
HZ & 2.837 & - & 0.171 & 0.217 & 0.228 & 0.424 \\
SM & 1.124 & 1.214 & - & 0.174 & 0.124 & 0.409 \\
EY & 0.849 & 0.904 & 1.186 & - & 0.101 & 0.340 \\
LS & 0.689 & 0.844 & 1.763 & 2.216 & - & 0.372 \\
MG & 0.327 & 0.339 & 0.362 & 0.486 & 0.422 & - \\
\hline
\end{tabular}

通种群和会泽种群所在的第I亚类群体中包含有最 多的特有单倍型(6种)。

\section{讨论}

\section{1 滇杨种群遗传多样性}

使用SSR和cpDNA两种分子标记确定种群内部 和种群之间的遗传多样性水平的方法已经被广泛 应用(Závada et al, 2017; Nicoletta et al, 2017; Shen et al, 2017)。在本研究中, 基于SSR标记的结果显示, 滇杨种群的遗传多样性 $(\mathrm{Ho}=0.552, \mathrm{He}=0.472)$ 与 毛白杨(P. tomentosa) (Ho =0.572, He = 0.446)(Du et al, 2012)、欧洲黑杨(P. nigra) $(H o=0.337, H e=$ 0.466) (Jiang et al, 2015)的遗传多样性水平相似，但 低于同属近缘种青杨派(Section Tacamahaca)杨树

表7 滇杨叶绿体片段13个单倍型间的序列变异位点表

Table 7 Mutation sites of 13 haplotypes in chloroplast DNA fragments of Populus yunnanensis

\begin{tabular}{|c|c|c|c|c|c|c|c|c|c|c|c|c|c|c|c|c|c|c|c|c|c|c|c|c|c|c|c|c|c|c|c|c|c|c|c|}
\hline \multirow{6}{*}{$\begin{array}{l}\text { 单倍 } \\
\text { 型 } \\
\text { Hap- } \\
\text { lotype }\end{array}$} & \multicolumn{35}{|c|}{ 变异位点 Mutation sites } \\
\hline & \multicolumn{21}{|c|}{$\mathrm{CO} 2$} & \multicolumn{8}{|c|}{$\mathrm{CO} 5$} & \multicolumn{6}{|c|}{ CO9 } \\
\hline & & & & & & & & & & & & & & & & & 1 & 1 & 1 & 1 & 1 & 1 & 2 & 2 & 2 & 2 & 2 & 2 & 2 & 3 & 3 & 3 & 3 & 3 & 3 \\
\hline & 6 & 7 & 8 & 8 & 8 & 8 & 8 & 8 & 8 & 9 & 9 & 9 & 9 & 9 & 9 & 9 & 0 & 0 & 1 & 3 & 4 & 5 & 5 & 6 & 6 & 6 & 6 & 6 & 6 & 1 & 3 & 3 & 3 & 4 & 7 \\
\hline & 6 & 9 & 4 & 6 & 6 & 7 & 8 & 8 & 9 & 0 & 0 & 0 & 0 & 1 & 4 & 9 & 0 & 2 & 9 & 3 & 3 & 7 & 8 & 6 & 6 & 6 & 7 & 8 & 8 & 2 & 0 & 3 & 8 & 2 & 7 \\
\hline & 3 & 3 & 2 & 4 & 6 & 1 & 3 & 7 & 7 & 1 & 2 & 3 & 8 & 0 & 3 & 5 & 2 & 7 & 8 & 4 & 2 & 0 & 5 & 0 & 1 & 3 & 4 & 4 & 9 & 3 & 1 & 5 & 1 & 3 & 2 \\
\hline $\mathrm{H} 1$ & - & - & - & G & A & - & - & - & A & A & - & $\mathrm{C}$ & - & G & - & G & $\mathrm{C}$ & - & $\mathrm{C}$ & A & $\mathrm{C}$ & $\mathrm{T}$ & - & $\mathrm{C}$ & $\mathrm{T}$ & A & $\mathrm{C}$ & $\mathrm{C}$ & $\mathrm{C}$ & - & - & $\mathrm{T}$ & G & G & - \\
\hline $\mathrm{H} 2$ & . & . & . & . & . & . & . & . & . & . & . & G & . & . & . & . & . & . & . & . & . & C & . & . & . & . & . & . & . & . & . & . & . & . & . \\
\hline H3 & . & . & . & . & . & . & . & . & . & $\mathrm{C}$ & . & G & . & . & . & . & . & . & . & . & . & C & . & . & . & . & . & . & . & - & . & . & . & . & . \\
\hline H4 & . & . & . & A & $\mathrm{G}$ & A & $\mathrm{T}$ & A & . & . & . & G & . & A & $\mathrm{T}$ & . & . & . & . & . & - & . & . & . & . & . & . & . & . & . & . & . & . & . & . \\
\hline H5 & . & . & . & . & . & . & . & . & . & . & . & G & . & . & . & . & . & . & . & . & . & $\mathrm{C}$ & $\mathrm{G}$ & . & . & . & . & . & . & . & . & . & . & . & . \\
\hline H7 & . & $\mathrm{T}$ & . & . & . & . & . & . & . & . & . & G & . & . & . & . & $\mathrm{T}$ & . & $\mathrm{T}$ & . & $\mathrm{T}$ & . & G & . & . & . & . & . & . & A & . & . & . & . & . \\
\hline H8 & . & . & . & . & . & . & $\mathrm{T}$ & C & $\mathrm{T}$ & . & . & G & . & . & . & . & . & C & . & . & $\mathrm{T}$ & C & . & . & . & . & . & . & . & . & . & . & . & . & . \\
\hline H9 & . & . & . & . & . & . & . & . & . & . & . & G & . & . & . & A & . & . & . & . & . & C & . & . & . & . & . & . & . & . & $\mathrm{T}$ & G & . & . & . \\
\hline H10 & . & . & . & . & $\cdot$ & . & . & . & . & . & . & G & . & . & . & . & . & . & . & . & . & $\mathrm{C}$ & . & . & . & . & . & A & - & . & . & . & . & . & . \\
\hline H11 & . & · & . & . & . & . & . & . & . & . & A & G & . & . & . & . & . & . & . & . & . & C & . & . & . & . & . & . & . & . & . & . & . & A & . \\
\hline H12 & $\mathrm{G}$ & . & . & - & $\mathrm{G}$ & A & . & . & . & A & . & G & . & . & . & . & . & . & . & . & . & C & . & . & . & . & . & . & . & . & . & . & . & . & . \\
\hline H13 & . & . & . & . & . & . & . & . & . & . & . & G & . & . & . & . & . & . & . & . & . & C & . & - & - & $\mathrm{T}$ & - & A & - & . & . & . & . & . & A \\
\hline
\end{tabular}



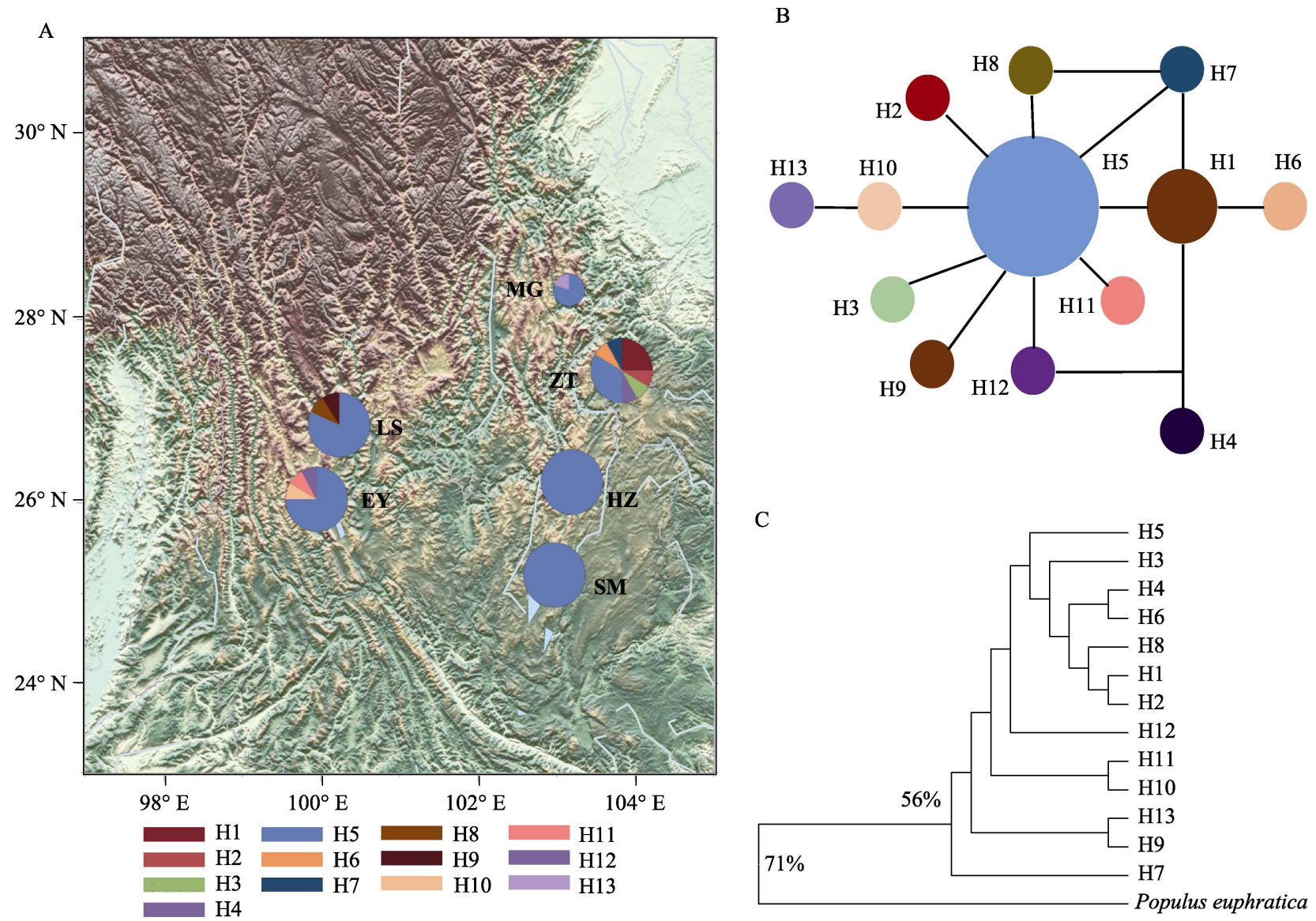

图3 滇杨基于cpDNA的单倍型网络图。(A)单倍型地理分布图, 圆大小代表种群个体数多少, 饼状图为各单倍型占比; (B)中 央网络连接图; (C)最大简约法树(MP), 百分比表示1,000次bootstrap值的比例，小于 $50 \%$ 的不予显示。种群代号同表1。

Fig. 3 Haplotype network of Populus yunnanensis based on cpDNA. (A) Haplotype geographical distribution map. The circle size represents the number of individuals in the population. Size of pie charts is proportional to the numbers of individuals sequenced in each population. (B) Median-joining network; (C) The maximum parsimony consensus tree (MP). The percentage of replicate trees in which the associated taxa clustered together in the bootstrap test (1,000 replicates) are shown next to the branches. Branches corresponding to partitions reproduced in less than $50 \%$ bootstrap replicates are collapsed. Population codes see Table 1.

青杨 $(P$. cathayana $)(H o=0.771, H e=0.512)($ 彭幼红, 2006), 表明滇杨遗传多样性处于中等水平。地理分 布范围是决定遗传多样性的主要因素之一, 分布范 围广的物种会有更高的遗传多样性(Hamrick et al, 1992; 陈小勇, 2000)。滇杨天然种群具有丰富的遗 传多样性, 应该与云南地区本身气候地貌条件多变 复杂，拥有大量的树种类型有关; 而滇杨的遗传多 样性小于青杨, 则可能是由于青杨的种群分布范围 更广(徐伟英, 1988)。

\section{2 滇杨种群间遗传分化及遗传结构}

基于 SSR 和 cpDNA 两种分子标记手段的 AMOVA分析显示, 滇杨种群遗传分化系数分别为 0.237 和 0.148 , 总的基因流大小为 0.806 , 且两种分 子标记均显示有 $80 \%$ 以上的变异来自种群内, 只有
少部分变异因素来自种群间, 这源于木本植物风媒 与花粉传播的特性(DiFazio et al, 2011), 即种群内 遗传变异水平较高, 而种群间遗传变异水平较低。 相比于其近缘种青杨种群基于SSR的遗传分化系数 (为 0.258 , 彭幼红, 2006), 滇杨的遗传分化程度中 等。DAPC分析以及UPGMA聚类结果表明滇杨在遗 传结构上可以分为 3 个亚类，同一亚类内遗传分化 小、基因流大，而不同亚类间种群的遗传分化大、 基因流小; 从聚类关系上可以看出地理位置相近的 种群聚为一类, 这表明滇杨种群间具有明显的地理 区域特性。

\section{3 滇杨谱系地理学分析}

在缺少确切的孢粉数据和化石数据的情况下, 对冰期避难所的位置确定可以参考以下原则：第 
一、包含原始单倍型的种群所在位置; 第二、单倍 型多样性高的种群所处的位置(Posada \& Crandall, 2001)。从这个角度来看, 滇杨的单倍型分布中H5 占有最大的比例, 在各个种群中都有分布, 系统发 育关系中也最早形成(被划分出来)。所以H5单倍型 属于滇杨种群中的祖先单倍型, 其他的单倍型都是 种群所特有的单倍型, 其中昭通种群的特有单倍型 最多, 有6种。从谱系地理学的角度来看, 昭通种群 所在地区极有可能是滇杨的冰期避难所, 加上昭通 位于云贵高原与四川盆地的汇合区域, 属于典型的 山地地形, 群山䇯立, 地形比较复杂, 也为避难所 的存在提供了非常有利的条件(Qiu et al, 2011)。同 时, 昭通种群的遗传多样性高也为其是否可能为杂 交带引发了争议。杂交带的形成是由于不同避难所 中扩张出来的种群相遇形成的区域, 会表现出高的 遗传多样性, 在这一点上与避难所种群会产生混 淆。一种有效区分避难所与杂交带的方法是避难所 内部的单倍型在亲缘关系上会更近一些, 而避难所 之间的单倍型在亲缘关系上则会相对更远一些(白 伟宁和张大勇, 2014)。在本研究中比较昭通地区(ZT) 包含的特有单倍型的亲缘关系可以看出, H1、H2、 H3、H4、H6、H7这些昭通地区特有的单倍型比其 他单倍型表现出了更近的亲缘关系(图3C), 表明昭 通地区(ZT)可能更偏向于避难所。

\section{4 滇杨资源保护策略}

遗传多样性和遗传结构地研究是制定物种保 护措施的前提条件, 也是科学合理地利用种质资源 和改进遗传特性的理论基础。本研究发现滇杨种群 的遗传多样性处于中等水平, 在实地调查采样中也 发现滇杨的生存环境受人类活动影响较大, 应及时 采取措施，保证合理地利用和有效地保护。

昭通种群具有最多的特有单倍型(6种)和较高 的核苷酸多样性(0.550), 遗传多样性水平高(0.864), 在所采集的所有样本中, 它所包含的基因种类最为 丰富, 因此有必要对这个种群进行重点保护。其他 种群尽管单倍型种类较少, 但那些特有单倍型也需 要加强保护。根据本研究, 滇杨的保护策略可以从 就地保护和建立种质资源圃这两个方面开展。滇杨 的遗传结构将滇杨按照地理位置分成了 3 个亚类群, 即云南东南部的亚类群I、云南西北部的亚类群II和 四川地区的亚类群III, 因此可以选择在这 3 个地方 进行就地保护, 针对树龄较大的滇杨可进行挂牌保
护。在对种群进行就地保护的过程中，应该着重于 种群范围的扩大以及种群间基因流的增强，进一步 提升滇杨的遗传多样性。另外，建议建立滇杨的种 质资源圃，最大限度地保存滇杨的种质资源，有利 于对滇杨材性、适应性、抗逆性等各方面进行深入 研究。作为一种稀有而典型的南方型杨树种，目前 对滇杨种质资源的开发利用还需要进一步加强，尽 早选育出适应南方生态气候的杨树优良种质，将对 杨树在南方的普及和推广产生巨大影响。

致谢：本文的调查工作得到了西南林业大学何承忠 教授、四川省林业科学研究院罗建勋研究员及其他 人员的大力支持和协助，特此感谢！同时感谢审稿 专家提出的宝贵意见和建议, 使本文更加严谨!

\section{参考文献}

Allen G, Flores-Vergara M, Krasynanski S, Kumar S, Thompson WF (2006) A modified protocol for rapid DNA isolation from plant tissues using cetyltrimethylammonium bromide. Nature Protocols, 1, 2320-2325.

Bai WN, Zhang DY (2014) Current status and future directions in plant phylogeography. Chinese Bulletin of Life Sciences, 26, 125-137. (in Chinese with English abstract) [白伟宁, 张大勇 (2014) 植物亲缘地理学的研究现状与发展趋势. 生命科学, 26, 125-137.]

Bandelt HJ, Forster P, Röhl A (1999) Median-joining networks for inferring intraspecific phylogenies. Molecular Biology and Evolution, 16, 37-48.

Burland TG (2000) DNASTAR's Lasergene sequence analysis software. Methods in Molecular Biology, 132, 71-91.

Chen K (2007) Genetic Relationships among Poplar Species in Section Tacamahaca Spach from Western Sichuan of China. $\mathrm{PhD}$ dissertation, Chengdu Institute of Biology, Chinese Academy of Sciences, Chengdu. (in Chinese with English abstract) [陈珂 (2007) 川西青杨组(Section Tacamahaca Spach)不同种的亲缘关系分析. 博士学位论文, 中国科学 院成都生物研究所, 成都.]

Chen XM, He ZH, Shi JR, Xia LQ, Rick W, Zhou Y, Jiang GL (2003) Genetic diversity of high quality winter wheat varieties (lines) based on SSR markers. Acta Agronomica Sinica, 29, 13-19. (in Chinese with English abstract) [陈新 民，何中虎，史建荣，夏兰芹，Ward Rick，周阳，蒋国梁 (2003) 利用SSR标记进行优质冬小麦品种(系)的遗传多 样性研究. 作物学报, 29, 13-19.]

Chen XY (2000) Effects of habitat fragmentation on genetic structure of plant populations and implications for the biodiversity conservation. Acta Ecologica Sinica, 20, 884-892. (in Chinese with English abstract) [陈小勇 (2000) 
生境片断化对植物种群遗传结构的影响及植物遗传多样 性保护. 生态学报, 20, 884-892.]

Crandall KA, Templeton AR (1993) Empirical tests of some predictions from coalescent theory with applications to intraspecific phylogeny reconstruction. Genetics, 134, 959-969.

DiFazio S, Slavov G, Rodgers-Melnick E, Martin J, Schackwitz W, Priya R, Tuskan G (2011) Inferring the evolutionary history of Populus trichocarpa from whole genome resequencing data. BMC Proceedings, 5, O1.

Du QZ, Wang B, Wei ZZ, Zhang DQ, Li BL (2012) Genetic diversity and population structure of Chinese white poplar (Populus tomentosa) revealed by SSR markers. Journal of Heredity, 103, 853-862.

Ferradini N, Lancioni H, Torricelli R, Russi L, Ragione ID, Cardinali I, Marconi G, Gramaccia M, Concezzi L, Achilli A, Veronesi F, Albertini E (2017) Characterization and phylogenetic analysis of ancient Italian landraces of pear. Frontiers in Plant Science, 8, 751.

Golding GB (1987) The detection of deleterious selection using ancestors inferred from a phylogenetic history. Genetics Research, 49, 71-82.

Gong GT (2004) The geographic distribution and origin of Populus L. Journal of Sichuan Forestry Science and Technology, 25(2), 25-30. (in Chinese with English abstract) [龚固 堂 (2004) 杨属地理分布与起源初探. 四川林业科技, 25 (2), 25-30.]

Hamrick JL, Godt MJW, Sherman-Broyles SL (1992) Factors influencing levels of genetic diversity in woody plant species. New Forests, 6, 95-124.

He CZ, Che PY, Peng CY, Zhou XT, Duan AA, Wang DX, Xin PY (2010) A survey of research progress on gene resources of Populus yunnanensis. Journal of Southwest Forestry University, 30(1), 83-88. (in Chinese with English abstract) [何承忠, 车鹏燕, 周修涛, 段安安, 王德新, 辛 培尧 (2010) 滇杨基因资源及其研究概况. 西南林业大 学学报, 30(1), 83-88.]

He CZ, Zhang ZY, Duan AA, Feng XL (2009) Genetic Diversity Analysis of Populus yunnanensis by AFLP Markers. China Forestry Publishing House, Beijing. (in Chinese) [何 承忠, 张志毅, 段安安, 冯夏莲 (2009) 滇杨基因资源遗 传多样性的AFLP分析. 中国林业出版社, 北京.]

Jia HX, Ji HJ, Hu JJ, Lu MZ (2015) Fingerprints of SSR markers and ploidy detection for new Populus varieties. Scientia Silvae Sinicae, 51(2), 69-79. (in Chinese with English abstract) [贾会霞, 姬慧娟, 胡建军, 卢孟柱 (2015) 杨树新 品种的SSR指纹图谱构建和倍性检测. 林业科学, 51(2), 69-79.]

Jiang DC, Wu GL, Mao KS, Feng JJ (2015) Structure of genetic diversity in marginal populations of black poplar (Populus nigra L.). Biochemical Systematics and Ecology, 61, 297-302.

Jombart T, Devillard S, Balloux F (2010) Discriminant analysis of principal components: A new method for the analysis of genetically structured populations. BMC Genetics, 11, 94.

Kumar S, Stecher G, Tamura K (2016) MEGA7: Molecular Evolutionary Genetics Analysis version 7.0 for bigger datasets. Molecular Biology and Evolution, 33, 1870-1874.

Peakall R, Smouse PE (2006) GENALEX 6: Genetic analysis in Excel. Population genetic software for teaching and research. Molecular Ecology Notes, 6, 288-295.

Peng YH (2006) Population Genetic Survey of Populus cathayana Rehd. Originating from eastern edge of Qinghai-Tibetan Plateau of China. PhD dissertation, Chengdu Institute of Biology, Chinese Academy of Sciences, Chengdu. (in Chinese with English abstract) [彭幼红 (2006) 青藏高原 东缘青杨(Populus cathayana Rehd.)遗传多样性研究. 博 士学位论文, 中国科学院研究生院成都生物研究所, 成 都.]

Polzin T, Daneshmand SV (2003) On Steiner trees and minimum spanning trees in hypergraphs. Operations Research Letters, 31, 12-20.

Posada D, Crandall KA(2001) Intraspecific gene genealogies: Trees grafting into networks. Trends in Ecology \& Evolution, 16, 37-45.

Qiu YX, Fu CX, Comes HP (2011) Plant molecular phylogeography in China and adjacent regions: Tracing the genetic imprints of Quaternary climate and environmental change in the world's most diverse temperate flora. Molecular Phylogenetics and Evolution, 59, 225-244.

Retief JD (1999) Phylogenetic analysis using PHYLIP. Methods in Molecular Biology, 132, 243-258.

Roy JK, Lakshmikumaran MS, Balyan HS, Gupta PK (2004) AFLP-based genetic diversity and its comparison with diversity based on SSR, SAMPL, and phenotypic traits in bread wheat. Biochemical Genetics, 42, 43-59.

Rozas J, Sánchez-DelBarrio JC, Messeguer X, Rozas R (2003) DnaSP, DNA polymorphism analyses by the coalescent and other methods. Bioinformatics, 19, 2496-2497.

Schuelke M(2000) An economic method for the fluorescent labeling of PCR fragments. Nature Biotechnology, 18, 233-234.

Semerikova SA, Semerikov VL (2014) Molecular phylogenetic analysis of the genus Abies (Pinaceae) based on the nucleotide sequence of chloroplast DNA. Genetika, 50, 12-25.

Shang ZH, Yao AX (2002) Biological genetic diversity research methods and their protective measures. Journal of Ningxia Agricultural College, 23(1), 66-69. (in Chinese) [尚 占环, 姚爱兴 (2002) 生物遗传多样性研究方法及其保 护措施. 宁夏农学院学报, 23(1), 66-69.]

Shen XF, Wu ML, Liao BS, Liu ZX, Bai R, Xiao SM, Li XW, Zhang BL, Xu J, Chen SL (2017) Complete chloroplast genome sequence and phylogenetic analysis of the medicinal plant Artemisia annua. Molecules, 22, 1330.

Tippmann HF (2004) Analysis for free: Comparing programs for sequence analysis. Briefings in Bioinformatics, 5, 82-87.

Wan XQ, Zhang F, Zhong Y, Wang CL, Ding YH, Hu TX, 
Zhai MP, Qian ZL (2009) Conservation and application of the genetic resource of native poplars in Southwest China. Scientia Silvae Sinicae, 45(4), 139-144. (in Chinese with English abstract) [万雪琴, 张帆, 钟宇, 王长亮, 丁云海, 胡庭兴, 翟明普, 钱宗亮 (2009) 中国西南地区乡土杨树 基因资源的保护与利用. 林业科学, 45(4), 139-144.]

Wang J, Li ZJ, Guo QH, Ren GP, Wu YX (2011) Genetic variation within and between populations of a desert poplar (Populus euphratica) revealed by SSR markers. Annals of Forest Science, 68, 1143-1149.

Wang JL, Gao QB, Fu PC, Gulzar K, Chen SL, Zhang FQ (2014) Phylogeography of Spiraea mongolica (Rosaceae) on the Qinghai-Tibetan Plateau and adjacent highlands. Acta Botanica Boreali-Occidentalia Sinica, 10, 1981-1991. (in Chinese with English abstract) [王久利, 高庆波, 付鹏程, Gulzar K, 陈世龙, 张发起 (2014) 青藏高原及其毗邻山 区蒙古绣线菊谱系地理学研究. 西北植物学报, 34, 1981-1991.]

Xu WY (1988) Poplar. Heilongjiang People’s Publishing House. Harbin. (in Chinese) [徐纬英 (1988) 杨树. 黑龙江 人民出版社, 哈尔滨.]

Yan LQ, Li JM, Yuan T, Zhou AP, Zong D, Li D, Xin PY, He CZ (2016) Genetic diversity analysis of Populus yunnanensis by SRAP markers. Biotechnology Bulletin, 32, 159-167. (in Chinese with English abstract) [颜璐茜, 李佳曼, 员涛, 周 安佩, 纵丹, 李旦, 辛培尧, 何承忠 (2016) 滇杨遗传多 样性的SRAP分析. 生物技术通报, 32, 159-167.]

Yu SQ, Liu J, Fu DR, Liu DJ, Liu YQ (2003) Characteristics of Tacamahaca genes in the Western Sichuan Plateau. Journal of Zhejiang Forestry College, 20, 27-31. (in Chinese with
English abstract) [余树全, 刘军, 付达荣, 刘大健, 刘友全 (2003) 川西高原青杨派基因资源特点. 浙江林学院学报, 20(1), 27-31.]

Závada T, Malik RJ, Kesseli RV (2017) Population structure in chicory (Cichorium intybus): A successful U. S. weed since the American revolutionary war. Ecology and Evolution, 7, 4209-4219.

Zeng YF, Zhang JG, Abuduhamiti B, Wang WT, Jia ZQ (2018) Phylogeographic patterns of the desert poplar in Northwest China shaped by both geology and climatic oscillations. BMC Evolutionary Biology, 18, 75.

Zhao N, Liu J (1994) Taxonomic studies on Populus L. in Southwestern China (II). Journal of Wuhan Botanical Research, 9, 225-232. (in Chinese with English abstract) [赵能, 刘军 (1994) 中国西南地区杨属的分类学研究(II). 武汉 植物科学学报, 9, 225-232.]

Zheng HL, Fan LQ, Milne RI, Zhang L, Wang YL, Mao KS (2017) Species delimitation and lineage separation history of a species complex of aspens in China. Frontiers in Plant Science, 8, 375.

Zong D, Yuan T, Zhou AP, Liu DY, Zheng Y, Duan AA, He CZ (2014) Analysis of genetic background of 52 Populus yunnanensis superior trees by AFLP markers. Journal of Northwest Forestry University, 29, 103-108. (in Chinese with English abstract) [纵丹, 员涛, 周安佩, 刘东玉, 郑 元, 段安安, 何承忠 (2014) 滇杨优树遗传多样性的 AFLP分析. 西北林学院学报, 29, 103-108.]

(责任编委: 邱英雄 责任编辑: 时意专) 